\title{
Trypanocidal activity of ethanolic extracts of Commiphora swynnertonii Burtt on Trypanosoma congolense
}

\author{
Yakob P. Nagagi ${ }^{1,2^{*}}$, Richard S. Silayo ${ }^{1}$ and Eliningaya J. Kweka ${ }^{2,3}$
}

\begin{abstract}
Background: African trypanosomosis is the disease caused by extracellular protozoan parasites of the genus Trypanosoma transmitted by tsetse flies. The current study has evaluated the trypanocidal activity of Commiphora swynnertonii extracts on Trypanosoma congolense.

Methods: The effect of ethanolic stem bark and resinous extracts on motility of $T$. congolense was evaluated by in vitro study at concentrations of $2 \mathrm{mg} / \mathrm{ml}$ and $4 \mathrm{mg} / \mathrm{ml}$. Then, trypanocidal activity was evaluated by drug incubation infectivity test using mice at concentrations of $0.4 \mathrm{mg} / \mathrm{ml}$ and $2 \mathrm{mg} / \mathrm{ml}$. In both studies negative (without drug) and positive (diminazene diaceturate) controls were used.

Results: The in vitro study showed that, ethanolic stem bark extract of C. swynnertonii at concentration of $4 \mathrm{mg} / \mathrm{ml}$ caused complete cessation of motility for T. congolense in $30 \mathrm{~min}$. However, resinous ethanolic extract had delayed effect on cessation of motility of T. congolense observed at 90 and 100 min post-incubation at concentrations of $4 \mathrm{mg} /$ $\mathrm{ml}$ and $2 \mathrm{mg} / \mathrm{ml}$ respectively. The drug incubation infectivity test study depicted that ethanolic stem bark extract at concentration of $2 \mathrm{mg} / \mathrm{ml}$ significantly $(p=0.000)$ reduced the infectivity of $T$. congolense in mice. However, it did not vary significantly $(P=0.897)$ with group treated with diminazene diaceturate incubated mixture.

Conclusion: The current study has provided evidence that, ethanolic stem bark extract of C. swynnertonii possess trypanocidal activity against $T$. congolense. Based on these findings, further studies are recommended to determine its potential as a lead to trypanocidal drug discovery.
\end{abstract}

Keywords: Trypanocidal activity, Commiphora swynnertonii, Trypanosoma congolense

\section{Background}

African trypanosomosis also known as "sleeping sickness" in human or "nagana" in animals is caused by extracellular protozoan parasites of the genus Trypanosoma transmitted by tsetse flies [1]. While nagana has an appreciable contribution to low livestock productivity in rural areas [2], sleeping sickness is disabling and fatal disease that has however remained a neglected tropical disease contributing to rural underdevelopment [3-5]. About 70 million people distributed in approximately 1.55 million $\mathrm{km}^{2}$ are

\footnotetext{
* Correspondence: petnagagi@yahoo.com

'Department of Veterinary Microbiology and Parasitology, Faculty of Veterinary Medicine, Sokoine University of Agriculture, P. O. Box 3019, CHUO KIKUU, Morogoro, Tanzania

${ }^{2}$ Division of Livestock and Human Diseases Vector Control, Tropical Pesticides Research Institute, P.O. Box 3024, Arusha, Tanzania

Full list of author information is available at the end of the article
}

at various risk levels of acquiring sleeping sickness in Africa [6]. On the other hand, nagana is known to reduce income accrued to livestock production up to $50 \%$ and is distributed in approximately 10 million $\mathrm{km}^{2}$ in Africa leaving many in abject poverty [2, 7]. In Tanzania, nagana is second to East Coast Fever (ECF) in causing cattle mortalities [8].

Nagana has been mainly controlled by the use of chemotherapy. However, chemotherapeutic options are very limited and currently available drugs for use are diminazene diaceturate and isometamidium chloride [9]. The later is a molecule developed by combining diminazene and homidium [10].

Plants have been the source of most active medical compounds for decades in Africa. Commiphora swynnertonii (family Burseracea) is one of the plant species 
reported to possess a multifaceted range of ethnobotanical use amongst Dorobo (sub-ethnic group of Masaai tribe) people in Tanzania [11]. It has been claimed to be used for treatment of sexually transmitted diseases, ulcers and wounds (cut wounds and burn wounds), recalcitrant ulcers, abscesses, swelling of legs, chesty cough and scabies [11]. Its resinous exudates are used for treatment of worm infestation and dental caries, cleansing bladder and control of insects such as ticks, lice, bed bugs and mange mites [11]. In fact, previous studies have established plenitude of knowledge about C. swynnertonii that have provided pragmatic documents to support its traditional use. Bakari and others [12] reported that resin and root ethanolic extract possess strong anti-microbial activity against Streptococcus pyogenes, Escherichia coli, Bacillus subtilis and Candida albicans. Chloroform leaf extracts have been shown to possess highest activity against Vibrio cholera, Shigella flexineri and Cryptococcus neoformans [13]. On the other hand, resinous ethanolic extract has also been shown to possess strong antiviral activity against Newcastle disease virus [14, 15], and anticoccidial activity on Eimeria species in chicken [16]. Additionally, essential oils of C. swynnertonii leaves have been shown to possess repellent effect on Rhipicephalus appendiculutus whereas the hexane and ethyl acetate bark extracts were reported to induce mortality to both nymphs and adults of $R$. appendiculatus [17, 18]. Notably, there is also a recent confirmation of strong acaricidal activity possessed by $C$. swynnertonii exudates [19].

Plant extracts have been found to have antitrypanosomal activity against trypanosomes in different plant extracts evaluated in vitro [20]. Considering the previous reports on C. swynnertonii extracts activity, there is none which directly underpins the basis of our current study. The basis of this study was; (i) information on its anticoccidial activity against Eimeria species which are protozoan parasites, (ii) evidence of in vitro trypanocidal activity of C. kerstingii in Nigeria [21] and (iii) hypothesis which was developed based on the literature evidence that sesquiterpenes are among the phytochemical compounds in Commiphora species [22] with various forms reported to possess trypanocidal activity in vitro and in vivo [23]. Therefore, this study presents the report on the evaluation of extracts of Commiphora swynnertonii Burtt against Trypanosoma congolense by in vitro and drug incubation infectivity test.

\section{Methods}

\section{Plant materials}

Stem pieces and resin of Commiphora swynnertonii were collected from Kitwai A village $\left(4^{\circ} 05^{\prime} 42.00\right.$ S and 36 $33^{\prime}$ 34.42 E), Simanjiro district which is in the northern part of Tanzania. The plant specimen was submitted to National Herbarium of Tanzania, Tropical Pesticides Research
Institute, Arusha (Specimen voucher Number CS..01). Confirmation was done by Mr. Emmanuel Mboya and plant specimen deposited at the herbarium. The collected plant materials were transported to Sokoine University of Agriculture for preparation, extraction and in vitro and in vivo testing.

\section{Plant extract preparation}

The resin was stored in a refrigerator at $4{ }^{\circ} \mathrm{C}$ while the stem bark peeled off and dried under shade for about 4 weeks. Dried bark was ground to fine powder using laboratory mill and stored in an airtight bag in cool dry room until used. Two hundred gram $(200 \mathrm{~g})$ of the ground stem bark was weighed and soaked in $400 \mathrm{ml}$ of 99.9 \% ethanol in a conical flask sealed with aluminium foil and left for $72 \mathrm{~h}$ in a dark place with occasional stirring after which it was first filtered using a piece of cotton wool in a funnel into a conical flask and then using Whatmann ${ }^{\circ}$ filter paper No. 1. The obtained filtrate was put in beaker and concentrated under ceiling fan at room temperature. The resin was treated differently. After soaking, the ethanol was immediately evaporated at room temperature under ceiling fan. The resulting crude extracts were then stored at $4{ }^{\circ} \mathrm{C}$ in airtight bottles until used.

Two (2) grams of both resinous and stem bark extracts were weighed in a bijou bottle separately and each diluted with $10 \mathrm{mls}$ of phosphate buffered saline with glucose (PBSG) (pH, 8.0) to make $200 \mathrm{mg} / \mathrm{ml}$ stock solution. Two other extract concentrations $(10 \mathrm{mg} / \mathrm{ml}$ and $20 \mathrm{mg} / \mathrm{ml})$ were prepared from stock solutions by serial dilutions using PBSG. The extract solutions were prepared just before use and labeled accordingly while the remaining stock solutions stored in a refrigerator at $4{ }^{\circ} \mathrm{C}$ until required.

\section{Trypanosome stock}

The trypanosome stock used in this study was a stabilate of putative drug sensitive strain Trypanosoma congolense originally isolated from Mikese, Morogoro. This strain is maintained by serial passage in Swiss albino mice at the Small Animal Unit of the Faculty of Veterinary Medicine, Sokoine University of Agriculture. Trypanosomes used to undertake the studies were from mice detected parasitaemic (1.26-2.51 x $10^{8}$ trypanosomes per milliliter of blood) $4-5$ days post inoculation.

\section{Determination of parasitic load}

The parasitic load in mice was monitored in blood from the tail, pre-sterilized with methylated spirit. The number of parasites per milliliter was estimated microscopically at $\times 400$ magnification as per Herbert and Lumsden [24]. This involved counting of parasites per field in pure blood or blood diluted with buffered phosphate saline with glucose $(\mathrm{pH}, 8.0)$. Logarithm values of these counts 
were obtained by matching with table of Herbert and Lumsden [24] and converted to antilog to provide absolute number of trypanosomes per milliliter of blood.

\section{In vitro test for trypanocidal activity}

In assessing the in vitro anti-trypanosomal activity, $5 \mu \mathrm{l}$ from the prepared stock resinous and stem bark extracts $(10 \mathrm{mg} / \mathrm{ml}$ and $20 \mathrm{mg} / \mathrm{ml})$ were drawn and poured into separate labeled eppendorf tubes. For reference purposes, three other eppendorf tubes were included, one with $5 \mu \mathrm{l}$ of PBSG without the plant extract and the other containing $5 \mu \mathrm{l}$ of $10 \mathrm{mg} / \mathrm{ml}$ and $20 \mathrm{mg} / \mathrm{ml}$ diminazene diaceturate (Veriben ${ }^{\circ}$ Ceva Santé Animale, France). Test T. congolense-infected blood was collected from donor Swiss albino mice and diluted using PBSG to make estimated parasitic load of $3.16 \times 10^{7}$ trypanosomes per milliliter from which $20 \mu \mathrm{l}$ were drawn and poured into the labeled eppendorf tubes including negative (PBSG only) and positive (with diminazene aceturate) control to make effective concentrations of $2 \mathrm{mg} / \mathrm{ml}$ and $4 \mathrm{mg} / \mathrm{ml}$ of resinous, stem bark extracts and veriben ${ }^{\circ}$ respectively. These were gently mixed and allowed to stand in an incubator set at temperature of $37^{\circ} \mathrm{C}$ for $20 \mathrm{~min}$. Thereafter, about $2 \mu \mathrm{l}$ of the test mixture were placed on separate microscope slide and covered with cover slips and parasite observed after every $5 \mathrm{~min}$ for motility. Cessation or reduction in motility of the parasites in extract treated blood compared to that of the parasite loaded control blood without extract was taken as a measure of trypanocidal activity $[25,26]$.

\section{Drug incubation infectivity test \\ Experimental animals}

Random-bred male and female, Swiss albino mice 2-4 months old, weighing 25-40 g were used in carrying out the drug incubation infectivity test (DIIT). They were randomly put into six groups kept in plastic cages with wood shavings as beddings and identified with picric acid markings. They were fed with broiler mash (finisher) and tap water provided adequately.

\section{Reconstitution and incubation}

Resinous and stem bark extract concentrations of $20 \mathrm{mg} /$ $\mathrm{ml}$ and $100 \mathrm{mg} / \mathrm{ml}$ respectively were reconstituted from their $200 \mathrm{mg} / \mathrm{ml}$ stock solutions using PBSG. Diminazene diaceturate at $20 \mathrm{mg} / \mathrm{ml}$ to be used as treatment control was prepared from commercially available sachet (Veriben ${ }^{\circ}$, Ceva Santé Animale, France) using distilled water. Six eppendorf tubes were taken and labeled as G1, G2, G3, G4, G5 and G6. Thereafter, $10 \mu \mathrm{l}$ from the reconstituted preparations with amount of resinous extract per ml being 20, $100 \mathrm{mg}$ were put in eppendorf tubes G1, G2 respectively; stem bark extract 20, $100 \mathrm{mg}$ in eppendorf tubes G3, G4 respectively; diminazene diaceturate $20 \mathrm{mg} /$ $\mathrm{ml}$ in G5 while into tube G6 was put $10 \mu \mathrm{l}$ of PBSG. This was followed by addition of $490 \mu \mathrm{l}$ of diluted mouse blood containing $1.58 \times 10^{7}$ trypanosomes per milliliter prepared by diluting blood from donor mouse with PBSG at dilution rate of $1: 8$ and parasite concentration estimated by the method of Hubert and Lumsden [24]. Gentle mixing was done and incubated at $37^{\circ} \mathrm{C}$ for $30 \mathrm{~min}$.

\section{Study design}

Six groups each with five mice were inoculated intraperitoneally with $0.08 \mathrm{mls}$ of incubation mixture (containing extract, diminazene diaceturate or PBSG and trypanosome suspension) as shown in Table 1. For logistical reasons the recorded incubation time varied from 36-56 min. Post inoculation monitoring of mice for parasitaemia by wet smear examination was carried out daily in the first week and thereafter 2-3 times a week for 7 weeks. At least 20 high power fields (x 400) were examined before considering a sample negative.

\section{Data analysis}

The infection rate post inoculation for the drug incubation infectivity test experiment was determined. The least significance difference ( $L S D=0.05)$ was obtained by one way analysis of variance (ANOVA) using statistical package for social science (SPSS) version 16 (Chicago, SPSS Inc., USA).

\section{Results}

The motility of $T$. congolense after in vitro incubation with resinous and stem bark ethanolic extracts of Commiphora swynnertonii at concentration of $2 \mathrm{mg} / \mathrm{ml}$ and $4 \mathrm{mg} / \mathrm{ml}$ is shown in (Table 2). In this study, ethanolic stem bark extract at the concentration of $4 \mathrm{mg} / \mathrm{ml}$ caused complete cessation of the motility of $T$. congolense in $30 \mathrm{~min}$. Meanwhile, at the concentration of $2 \mathrm{mg} / \mathrm{ml}$, the trypanosomes were less motile. Complete cessation of motility was observed after $60 \mathrm{~min}$ of incubation. In contrast, the resinous extract at comparable concentrations as the stem bark imposed a minimal effect on trypanosomes. This varied from motile to less motile until complete cessation of motility was observed at 90 and $100 \mathrm{~min}$ for the concentrations of $2 \mathrm{mg} / \mathrm{ml}$ and $4 \mathrm{mg} / \mathrm{ml}$ respectively. Diminazene diaceturate imposed less motility

Table 1 Experimental groups, the type of treatment and the time elapsed before inoculation into mice

\begin{tabular}{llll}
\hline Group $(\mathrm{G})$ & Extract & Concentration & $\begin{array}{l}\text { Incubation } \\
\text { Period (Min.) }\end{array}$ \\
\hline 1 & Resinous & $0.4 \mathrm{mg} / \mathrm{ml}$ & 48 \\
2 & & $2 \mathrm{mg} / \mathrm{ml}$ & 44 \\
3 & Stem Bark & $0.4 \mathrm{mg} / \mathrm{ml}$ & 36 \\
4 & & $2 \mathrm{mg} / \mathrm{ml}$ & 52 \\
5 & Diminazene diaceturate & $0.4 \mathrm{mg} / \mathrm{ml}$ & 40 \\
6 & PBSG (control) & - & 56 \\
\hline
\end{tabular}


Table 2 Motility of T. congolense after in vitro incubation with various concentrations of C. swynnertonii extracts

\begin{tabular}{lllllllll}
\hline Test Mixture & \multicolumn{7}{l}{ Post Incubation follow up (minutes) } \\
\cline { 2 - 8 } & 25 & 30 & 40 & 50 & 60 & 70 & 80 & 90 \\
\hline Resinous 2 mg/ml & +++ & ++ & ++ & ++ & ++ & ++ & + & + \\
$\quad 4 \mathrm{mg} / \mathrm{ml}$ & ++ & ++ & + & + & + & + & + & - \\
Stem Bark 2 mg/ml & ++ & + & + & + & - & - & - & - \\
$\quad 4 \mathrm{mg} / \mathrm{ml}$ & + & - & - & - & - & - & - & - \\
Veriben 2 mg/ml & + & + & - & - & - & - & - & - \\
$\quad 4 \mathrm{mg} / \mathrm{ml}$ & + & - & - & - & - & - & - & - \\
PBSG (-ve control) & +++ & +++ & +++ & +++ & +++ & +++ & ++ & ++ \\
\hline
\end{tabular}

Key: +++ Very motile, ++ Motile, + Less motile, - None motile

on the trypanosomes, complete cessation of motility was observed at 30 and $40 \mathrm{~min}$ at concentrations of $4 \mathrm{mg} / \mathrm{ml}$ and $2 \mathrm{mg} / \mathrm{ml}$ respectively. The trypanosomes however were very motile to being motile until towards the end of the follow up at $100 \mathrm{~min}$ in the negative control.

Results for in vitro trypanosomes drug incubation, followed by an assessment of infectivity to mice are summarized in Table 3. All the mice in group 1 were found to be infected at day 4 post inoculation. There was variation in infectivity of trypanosomes in mice in group 2. The infection was seen on 3rd day whereas in day seven, all the mice were infected. In group 3, infection was seen on the 2nd day and all the mice were found infected on day 4 . Group 4 had one mouse infected at day 9 while the rest remained trypanosome free during the entire period of the experiment. None of the mice in group 5 had the infection. In group 6, infection was detected on the 2nd day and all the mice were infected on day 4 . Nevertheless, infectivity of T. congolense in G4 was reduced significantly $(p=0.000)$ with respect to G6 (group inoculated with infective diluted blood without drug) (Table 4). However, there was no significance difference ( $p=0.897)$ between G4 and G5.

\section{Discussion}

The findings of this study have demonstrated that, the stem bark extracts at concentration of $4 \mathrm{mg} / \mathrm{ml}$ caused complete cessation of motility of $T$. congolense within $30 \mathrm{~min}$ in the in vitro study of the ethanolic extracts of C. swynnertonii. This observation partly matches with that of a previous study whereby methanolic stem bark extract of $C$. kerstingii at concentrations of 2 and $4 \mathrm{mg} / \mathrm{ml}$ were both shown to cause complete cessation of motility on T. brucei brucei within $30 \mathrm{~min}$. [21] The slight difference observed might be attributed to biochemical variations within species, geographical location, methods or mode of extraction, solvent used [27], and the season at which the plant material harvested [28]. On the other hand, the resinous extract had lower observed effect on the motility of $T$. congolense with cessation of motility observed at 90 and 100 min post incubation at concentrations of 4 and $2 \mathrm{mg} / \mathrm{ml}$ respectively. Among the extracts

Table 3 Proportions of mice positive for T. congolense Mikese parasitaemia after incubation with C. swynnertonii extracts

\begin{tabular}{|c|c|c|c|c|c|c|}
\hline \multirow[b]{3}{*}{$\begin{array}{l}\text { Days post } \\
\text { inoculation }\end{array}$} & \multicolumn{6}{|l|}{ Groups inoculated } \\
\hline & \multicolumn{6}{|c|}{ Number of mice infected/total mice present in the group } \\
\hline & $\begin{array}{l}\text { G1 } \\
\text { (resinous, } 0.4 \text { mg/ml) }\end{array}$ & $\begin{array}{l}\mathrm{G} 2 \\
\text { (resinous, } 2 \mathrm{mg} / \mathrm{ml} \text { ) }\end{array}$ & $\begin{array}{l}\text { G3 } \\
\text { (bark, } 0.4 \text { mg/ml) }\end{array}$ & $\begin{array}{l}\text { G4 } \\
\text { (bark, } 2 \mathrm{mg} / \mathrm{ml} \text { ) }\end{array}$ & $\begin{array}{l}\text { G5 } \\
\text { (dimin. diacet., } 0.4 \text { mg/ml) }\end{array}$ & $\begin{array}{l}\text { G6 } \\
\text { (PBSG, drug free) }\end{array}$ \\
\hline 0 & $0 / 5$ & $0 / 5$ & $0 / 5$ & $0 / 5$ & $0 / 5$ & $0 / 5$ \\
\hline 2 & $0 / 5$ & $0 / 5$ & $1 / 5$ & $0 / 5$ & $0 / 5$ & $1 / 5$ \\
\hline 3 & $0 / 5$ & $1 / 5$ & $3 / 5$ & $0 / 5$ & $0 / 5$ & $2 / 5$ \\
\hline 4 & $5 / 5$ & $2 / 5$ & $5 / 5$ & $0 / 5$ & $0 / 5$ & $5 / 5$ \\
\hline 6 & $5 / 5$ & $4 / 5$ & $5 / 5$ & $0 / 5$ & $0 / 5$ & $4 / 4$ \\
\hline 7 & $5 / 5$ & $5 / 5$ & $3 / 3$ & $0 / 5$ & $0 / 5$ & $2 / 2$ \\
\hline 8 & $4 / 4$ & $5 / 5$ & $2 / 2$ & $0 / 5$ & $0 / 5$ & $1 / 1$ \\
\hline 9 & $4 / 4$ & $5 / 5$ & $1 / 1$ & $1 / 5$ & $0 / 5$ & $1 / 1$ \\
\hline 14 & $3 / 3$ & $4 / 4$ & $1 / 1$ & $0 / 4$ & $0 / 5$ & $1 / 1$ \\
\hline 35 & $2 / 2$ & $2 / 2$ & $1 / 1$ & $0 / 4$ & $0 / 4$ & $1 / 1$ \\
\hline 45 & $1 / 1$ & $1 / 1$ & $1 / 1$ & $0 / 4$ & $0 / 4$ & $1 / 1$ \\
\hline 53 & 0 & $1 / 1$ & $1 / 1$ & $0 / 4$ & $0 / 4$ & 0 \\
\hline
\end{tabular}


Table 4 Infectivity of $T$. congolense in mice following drug incubation infectivity test of C. swynnertonii extract

\begin{tabular}{lllllll}
\hline$(\mathrm{I})$ & $\mathrm{J})$ & Mean & & & \multicolumn{2}{c}{95 \% Confidence Interval } \\
\cline { 5 - 6 } Groups treated & Groups treated & Difference $(I-J)$ & Standard Error & Significance level & Lower Bound & Upper Bound \\
\hline Groups treated & Groups treated & Difference $(I-J)$ & Standard Error & Significance level & Lower Bound & Upper Bound \\
G4 & G5 & .02222 & .17021 & .897 & $-.3200-$ & .3645 \\
& $G 6$ & -.71111 & .17021 & .000 & -1.0533 & -.3689 \\
\hline
\end{tabular}

of C. swynnertonii previously studied, resinous extract was shown to possess strong antimicrobial activity compared with stem bark, root bark and leaves extracts [29]. In contrast, this study has found that the stem bark extracts exhibit more in vitro antitrypanosomal activity than the resinous extract. A study conducted from 37 extracts in Tanzania have reported that, stem bark extracts of C. emenii possess strong in vitro antitrypanosomal activity relative to the other plant parts (leaves and root bark) [30].

Drug incubation infectivity tests showed that after incubation with mixture of ethanolic stem bark extract at concentration of $2 \mathrm{mg} / \mathrm{ml}$ for $52 \mathrm{~min}$ the reduction of infectivity of $T$. congolense Mikese compared to negative control was highly significant $(P=0.000)$. However, it did not vary significantly $(P=0.897)$ with group treated with diminazene diaceturate incubated mixture. Therefore, from drug incubation infectivity test experiment it was confirmed that the stem bark extracts of C. swynnertonii possess trypanocidal activity while resinous extract had no activity at similar concentrations. However, our current study should never be extrapolated to mean efficacy in vivo due to metabolic processes which occur in multicellular organisms. Both techniques used in this study, exposed the trypanosomes to a specified drug concentration, thereby avoiding potential problems such as drug distribution, drug half-life and bioavailability of the drug, and the behavior exhibited by the trypanosomes in the host. [24].

The current study has added C. swynnertonii Burtt to the list of plant species of similar genus (genus Commiphora) that were previously tested in vitro and found to possess antitrypanosomal activity. Other plant species included are C. kerstingii Engl. in Nigeria [21], and C. emenii Engl. in Tanzania [30]. The results of this study concur with the assumptions made by Freiburghaus and others that, antitrypanosomal effects might be due to phytochemical compounds universally existing in a plant genus [30]. These include tannins, phlobatannins, terpenoids, flavonoids, cardiac glycosides, steroids, saponins and anthraquinones which were confirmed to be contained in C. swynnertonii by Bakari [29]. Nevertheless, the trypanocidal principles of the species previously tested and the one tested in this study are still unknown. Although phytochemical analysis of various species of Commiphora have shown sesquiterpenes, a diverse group of terpenoids as among the chemical compounds [22], with various forms of sesquiterpenes reported to possess trypanocidal activity in vitro and in vivo [23], interpretation of our results based on the biochemical compound(s) responsible for the valid trypanocidal activity from genus Commiphora awaits further studies using selected biochemical components.

\section{Conclusion}

The current study has provided the first indication that ethanolic bark extracts of C. swynnertonii possess trypanocidal activity. Considering the two extracts (stem bark and resinous) of C. swynnertonii evaluated in this study, the phytochemical compound(s) responsible for antitrypanosomal activity may be well placed in the stem bark extract than in resinous extract. Therefore, studies are in progress to determine the potential of stem bark extract of C. swynnertonii as a trypanocidal drug and or alternative source of lead compound(s) for trypanocidal drug discovery.

\section{Abbreviations}

DIIT, Drug Incubation Infectivity Test; PBSG, Phosphate buffered saline with glucose

\section{Acknowledgements}

The authors would like to thank the Government of United Republic of Tanzania and the Tanzania Commission of Science and Technology (COSTECH) for Ph.D. studentship of Yakob P. Nagagi. The authors would also like to convey special thanks to Dr. Masaza Swalehe, Boniface Shongon, Elias Kihumo, Stewart Mwanyika and Dr. G. Bakari who provided their support at various stages in the course of this study.

Funding

The study received funds from Tanzania Commission for Science and Technology.

\section{Authors' contributions}

YPN conceived and conducted the study. YP Nagagi, RS Silayo and EJ Kweka searched and reviewed the literature and wrote up the manuscript. All edited and revised the manuscript critically. All authors reviewed the work and approved it for submission.

\section{Competing interests}

The authors declare that they have no competing interests.

\section{Consent for publication}

Not applicable.

\section{Ethics approval and consent to participate}

The study obtained ethical clearance by the research and publications committee of Sokoine University of Agriculture, Morogoro, Tanzania.

\section{Author details}

'Department of Veterinary Microbiology and Parasitology, Faculty of Veterinary Medicine, Sokoine University of Agriculture, P. O. Box 3019, CHUO KIKUU, Morogoro, Tanzania. ${ }^{2}$ Division of Livestock and Human Diseases Vector Control, Tropical Pesticides Research Institute, P.O. Box 3024, Arusha, Tanzania. ${ }^{3}$ Department of Medical Parasitology and Entomology, Catholic University of Health and Allied Sciences, P.O. Box 1464, Mwanza, Tanzania. 
Received: 24 February 2016 Accepted: 5 July 2016

Published online: 08 July 2016

\section{References}

1. Steverding D. The history of African trypanosomiasis. Parasit Vectors. 2008;1:3.

2. Swallow B. Impacts of Trypanosomiasis on African Agriculture. Rome: Food and Agriculture Organization of the United Nations (FAO); 2000.

3. Balasegaram M, Balasegaram S, Malvy D, Millet P. Neglected diseases in the news: a content analysis of recent international media coverage focusing on leishmaniasis and trypanosomiasis. PLoS Negl Trop Dis. 2008;2:e234.

4. Fèvre E, Wissmann B, Welburn S, Lutumba P. The Burden of Human African Trypanosomiasis. PLoS Negl Trop Dis. 2008;2:e333.

5. Malvy D, Chappuis F. Sleeping sickness. Clin Microbiol Infect. 2011;17:986-95.

6. Simarro P, Cecchi G, Franco J, Paone M, Diarra A, Ruiz-Postigo J, et al. Estimating and Mapping the Population at Risk of Sleeping Sickness. PLoS Negl Trop Dis. 2012;6:e1859.

7. Shaw A. Economics of African Trypanosomiasis. In: Maudlin I, Holmes PMM, editors. Trypanos. Wallingford: CABI Publishing; 2004. p. 369-402.

8. Daffa J. Tsetse and Trypanosomosis control activities in Tanzania, 2007-2009. In: AU-IBAR, editor. Proc. 30th Bienn. Conf. Int. Sci. Counc. Trypanos. Res. Control. Kampala, Uganda. Nairobi: AU-IBAR; 2011. p. 145.

9. Silayo R, Silayo F. Efficacy of repeat and combination treatment with Diminazene aceturate and/or Isometamidium chloride against drug resistant Trypanosoma congolense.. Tanzania Vet Bull. 1990;10:26-35.

10. Ellis $\mathrm{G}$, West $\mathrm{G}$, editors. Progress in Medicinal Chemistry. 3rd ed. London: Butterworth and Co. (Publishers) Limited; 1963.

11. Kalala W, Magadula J, Mdegela R. Ethnobotanical use of Commiphora swynnertonii Burtt. amongs Dorobo people in Tanzania. J Med Plant Res. 2014;8:820-8.

12. Bakari G, Max R, Mdegela R, Phiri E, Mtambo M. Antibacterial and antifungal activity of Commiphora swynnertonii (Burtt) against selected pathogens of public health importance. Res J Biol Sci. 2011;6:175-9.

13. Mkangara M, Chacha M, Kazyoba P. Antimicrobial and Cytotoxicity Efficacy of Commiphora swynnertonii (Burtt) Extracts. Int. J. Sci. Res. 2014;3:1611-5

14. Bakari G, Max R, Mdegela R, Phiri E, Mtambo M. Antiviral activity of crude extracts from Commiphora swynnertonii against Newcastle disease virus in ovo. Trop Anim Health Prod. 2012;44:1389-93.

15. Bakari G, Max R, Mdegela R, Phiri E, Mtambo M. Efficacy of resinous extract from Commiphora swynnertonii (Burtt) against Newcastle infection in chicken. Int J Med Plants Res. 2013;2:156-61.

16. Bakari G, Max R, Mdegela R, Phiri E, Mtambo M. Effect of resinous extract from Commiphora swynnertonii (Burtt) on experimental coccidial infection in chickens. Trop Anim Health Prod. 2012;45:455-9.

17. Kaoneka B, Mollel M. Acaricidal activities of extracts of Commiphora swynertonii Burtt (Burseraceae), Melia volkensii Gürke, Turraea abyssinica Hotchst, Turraea floribunda Hochst and Turraea cornucopia Styles \& F. White (Meliaceae) against the brown ear tick Rhipicephalus appendiculatus Neumann. J Open Univ Tanzania. 2012;10:25-34.

18. Kaoneka B, Mollel M, Lyatuu F. Leaf essential oil composition and tick repellency activity of Commiphora swynnertonii Burtt. J Biol Res. 2007;8:213-6.

19. Kalala W, Magadula J, Mdegela H. Evaluating Acaricidal activity of Commiphora swynnertonii (Burtt.) bark exudates against common ticks in Tanzania. Int J Herb Med. 2014;2:19-25.

20. Ibrahim M, Mohammed A, Isah M, Aliyu A. Anti-trypanosomal activity of African medicinal plants: A review update. J Ethnopharmacol. 2014;154:26-54

21. Mikail H. In vitro trypanocidal effect of methanolic extract of Sclerocarya birrea, Commiphora kerstingii and Khaya senegalensis. African J Biotechnol. 2009:8:2047-9.

22. Aliyu R, Gatsing D, Umar H. Antimicrobial activity and phytochemical screening of the leaves of Commiphora Africana. West African J Biol Sci. 2002;13:75-80.

23. Saeidnia S, Gohari A, Haddadi A. Biogenic trypanocidal sesquiterpenes: lead compounds to design future trypanocidal drugs - a mini review. DARU J. Pharm. Sci. 2013;21:35.

24. Herbert W, Lumsden W. Trypanosoma brucel: A Rapid Matching Method for Estimating Host Parasitemia. Exp Parasitol. 1976;40:427-31.

25. Atawodi S, Bulus T, Ibrahim S, Ameh D, Nok A, Mamman M, et al. In vitro Trypanocidal Effect of Methanolic Extract of Some Nigerian Savanna Plants. African J Biotechnol. 2003;2:317-21.
26. Ene A, Edeh N, Bonny-okoli C, Ojiako O, Ujowundu C, Igwe C. In vitro and in vivo Antitrypanosomal Effect of Methanol and Aqueous Extract of Picralima nitida. Br J Pharm Res. 2014;4:644-53.

27. Obaineh $\mathrm{O}$, Shadrach A. Phytochemical constituents and medicinal properties of different extracts of Anacardium occidentale and Psidium guajava. Asian J Biomed Pharm Sci. 2013;3:16

28. Chaves P, Santana C, Véras G, Brandão D, Felismino D, Medeiros A, et al. Seasonal variation in the production of secondary metabolites and antimicrobial activity of two plants species used in Brazilian traditional medicine. African J Biotechnol. 2013;12:847-53.

29. Bakari G. Biological Activity of Extracts from Commiphora swynnertonii against Microbes of Veterinary Importance in Chickens. PhD Thesis. Tanzania: Sokoine University of Agriculture; 2013.

30. Freiburghaus F, Jonker S, Nkunya M, Mwasumbi L, Brun R. In vitro trypanocidal activity of some rare Tanzanian medicinal plants. Acta Trop. 1997;66:79-83.

\section{Submit your next manuscript to BioMed Central and we will help you at every step:}

- We accept pre-submission inquiries

- Our selector tool helps you to find the most relevant journal

- We provide round the clock customer support

- Convenient online submission

- Thorough peer review

- Inclusion in PubMed and all major indexing services

- Maximum visibility for your research

Submit your manuscript at www.biomedcentral.com/submit
Biomed Central 